\title{
Legal Impact Assessment of Brexit: Clinical Trials Data Exchange and Data Protection
}

\author{
Lorelei Ana Garagancea and Walter Fürst*
}

\section{General Considerations}

Among the vast number of ways that Brexit will impact the life sciences sector are the consequences on data exchange in clinical trials. For life sciences, the outcome of Brexit depends, in a large part, on the level of alignment or divergence between the post-Brexit UK and the remaining 27 Member States of the European Union ('EU-27') in two key legislations: the EU General Data Protection Regulation ${ }^{1}$ (GDPR) and the (still) upcoming Clinical Trials Regulation ${ }^{2}$ ('CTR'). While the GDPR is already in force across the EU, before the UK is set to exit the EU, the CTR remains an open question even for the EU, let alone for the future potential alignment of the UK.

The conditions for the British exit from the EU will be set out in a Withdrawal Agreement ${ }^{3}$ whose negotiation process began upon the UK triggering of the Article 50 process of the Treaty on the European Union (TEU), ${ }^{4}$ on 29 March 2017. As an agreement is still largely disputed, this analysis focuses on the means to adopt mitigation measures, as available in the applicable legislation.

From a legal standpoint, the Withdrawal Agreement would be a treaty between EU and UK. EU treaties are entered into with third parties. Likewise, the Withdrawal Agreement can only become effective once the UK becomes a third country. The EU and the UK recently agreed to extend the initial withdrawal date, ie 30 March 2019, thus the UK will become a third country after this date. Upon finalization, a potential Withdrawal Agreement is subjected, from the EU side, to the ratification procedure for international agreements under article 218 TFEU, thus making it a rather lengthy process. ${ }^{5}$

During a transition period (currently agreed to end on 31 December 2020, with the possibility to extend it once with the agreement of the parties), the EU will treat the UK as if it were a Member State, with the exception of participation in the EU institutions and governance structures. ${ }^{\prime 6}$ At the end of the transition period, the UK will no longer be treated 'as an EU Member State (MS)'. However, without the UK's ratification of the Withdrawal Agreement, EU law will cease to apply to the UK as of the still under discussion withdrawal date (without any transition period).

According to the EU's official position, ${ }^{7}$ whatever the Brexit scenario, the UK will no longer be a member of any EU institutions, once the UK leaves the Union, as the EU is not willing to grant it the same rights and obligations as those arising from Union membership. Thus, the UK will no longer have a representative in the European Data Protection Board ('EDPB'), nor in the European Medicines Agency ('EMA'), because both institutions are created as a means of cooperation between EU Member States.

The aim of this report is to provide a twofold overview: on the one hand, of the consequences of a no-deal scenario between UK and EU; on the other hand, of several mitigation measures for addressing business risks entailed by the current uncertainties and by the future grey period between the withdrawal date and the applicability of the newly agreed

DOI: $10.21552 / \mathrm{ep} / \mathrm{r} / 2019 / 1 / 7$

* Lorelei Garagancea is Associate Legal Counsel at SFL. She has experience in supporting clients in the field of regulatory policy, legal affairs and data protection. For Correspondence: $<1$ .garagancea@sfl-services.com>. Walter Fürst is CSO and COO at SFL and has extensive expertise in medical communication of scientific evidence as well as stakeholder positions in the context of changing competitive and policy environments. For Correspondence:<w.fuerst@sfl-services.com>.

1 Regulation (EU) 2016/679 of the European Parliament and of the Council of 27 April 2016 on the protection of natural persons with regard to the processing of personal data and on the free movement of such data [2016] OJ L119/1.

2 Regulation (EU) No 536/2014 of the European Parliament and of the Council of 16 April 2014 on clinical trials on medicinal products for human use, and repealing Directive 2001/20/EC ('CTR') [2014] OJ L158/1.

3 Commission (EU) Draft Withdrawal Agreement on the withdrawal of the United Kingdom of Great Britain and Northern Ireland from the European Union and the European Atomic Energy Community (Withdrawal Agreement) 2018.

4 Maastricht Treaty, 1992, published in consolidated version in the EU OJ C 202/13 of 7 June 2016

5 Treaty on the Functioning of the European Union (TFEU), published in consolidated version in the EU OJ C 326/47 of 26 October 2012.

6 European Commission, 'Brexit Negotiations: What is in the Withdrawal Agreement' <http://europa.eu/rapid/press-release _MEMO-18-6422_en.htm> accessed 15 November 2018.

7 Council (EU) Political declaration setting out the framework for the future relationship between the European Union and the United Kingdom, XT 21095/18, 22 November 2018, 3. 
terms between the EU and UK. Such mitigation measures are conceived irrespective of the outcome of Brexit: from hard to soft Brexit or even Brexit in Name Only ('BINO', ie only a formal separation from the EU), or from an immediate to an open-end transition. This report does not aim at evaluating the level of regulatory alignment currently being explored in the UK in relation to the EU, as this may significantly change even in the very short time that remains. Instead, its goal is to explore the impact of different levels of divergence in some of the most relevant areas of health and privacy law.

The discussion is anchored around several core processes in clinical trials, including: the subsequent potential EU-UK cooperation for the purposes of the clinical trials 'EU database' created by the $\mathrm{CTR}^{8}$; the revision of Informed Consent Forms (ICFs) postGDPR; consent under GDPR in clinical trials; the transfers of data in and out of the EU at private companies' level or in the context of obtaining EU approval of new medicines. A question of concern is to what degree the UK can participate in EU regulatory schemes? Will the EU's position of not permitting the UK access to the EU database after Brexit become a reality?

Despite the many shades of Brexit, it appears likely that the post-Brexit UK will have at least some kind of aligned legislation and policies with the EU in the fields of public health and data protection, particularly when considering the European Parliament's position that it will only endorse a framework for the future EU-UK relationship if it ensures a level playing field in, among other, public health and data protection. ${ }^{9}$ However, several scenarios will be explored.

The impact of a 'hard' Brexit is mostly a reason of concern for companies active in highly regulated fields, like pharmaceuticals ${ }^{10}$ or as of rather recently, the handling of personal data. A 'hard' Brexit would mean issuing regulation in the UK different

\footnotetext{
8 The 'EU database', as defined by the CTR, art 81.

9 Parliament (EU) Motion B8xxxx/2018, no 4, 4.

10 British-Swiss Chamber of Commerce, 'Brexit White Paper' (2018) 6.

11 ibid 7.

12 Heather Stewart, 'Brexit bill: May under pressure after two big defeats in Lords' The Guardian (London, 18 April 2018).

13 The LIBE Committee, 'The implications of the United Kingdom's withdrawal from the European Union for the Area of Freedom, Security and Justice' (2017) <http://www.europarl.europa.eu/ RegData/etudes/STUD/2017/596824/IPOL_STU(2017)596824 _EN.pdf $>$ accessed 13 November 2018.
}

from the existing EU ones. For EU-based or overseas pharmaceutical companies, this would mean investing time and financial resources in achieving compliance with UK requirements coming on top of those they have to comply with for access to the large EU market. A significant impact is expected in connection to 'the certification and manufacturing of manufacturing plants or quality releases in individual countries. ${ }^{11}$ The below table explores scenarios from closest alignment of laws to no alignment at all.

\section{Clinical Data Exchanges}

In search for legal stability, ministers are expected by the UK Parliament to accept the substance of an amendment, which would keep the CTR - not yet applicable - in UK law. In particular, an amendment to the EU Withdrawal Bill was proposed by the House of Lords to ensure incorporation of the CTR into UK law. Upon reassurances from the Government, the amendment was apparently withdrawn. ${ }^{12}$ The UK Government may thus be preparing a close alignment of its domestic law to the CTR.

Even with the CTR closely implemented in British law, the EU has made it clear that a non-EU member cannot by principle have access to EU network and information systems and databases. It has been argued that, without the corresponding obligations of a Schengen member, ie increased level of information exchange, it is unlikely that the EU will grant UK access to the EU database recording clinical trials information, amongst other EU databases under debate. Besides, participation in this EU database is chiefly dependent on the UK complying with the EU standards on data protection. ${ }^{13}$ In other words, the future of the clinical data exchange of information between the EU and the UK is reliant on a decision on the future relationship in the field of data protection. This can entail potential business isolation for a certain period of time, until either alignment is ensured or until just enough Free Trade Agreements are concluded with as many countries as possible.

\section{Record Keeping and ICFs from a Personal Data Perspective}

In a clinical trial, personal data concerning health circulates from trial subjects to the health care profes- 
Comparative Table of Suggested Mitigation Measures for Several Brexit Scenarios

\begin{tabular}{|c|c|}
\hline Scenario post-Brexit & Mitigation measures at private sector level \\
\hline $\begin{array}{l}\text { An adequacy decision is issued by the EU Com- } \\
\text { mission }\end{array}$ & $\begin{array}{l}\text { Data can circulate rather easily between UK and EU MS. An adequacy } \\
\text { decision entails alignment to EU rules / incorporation of EU laws, so the } \\
\text { private sector may expect to be required to implement similar standards } \\
\text { of compliance in the UK as in the EU. }\end{array}$ \\
\hline $\begin{array}{l}\text { The Commission does not issue an adequacy } \\
\text { decision due to UK's refusal of the ECJ's jurisdic- } \\
\text { tion or due to the lack of agreement on a dispute } \\
\text { resolution mechanism. }\end{array}$ & $\begin{array}{l}\text { The private sector has to shift its attention to means of transferring } \\
\text { personal data under the special rules for transfers between EU and } \\
\text { third countries. Further details are provided under section 'Transfers of } \\
\text { data between EU and third countries' below and the annexed table. }\end{array}$ \\
\hline $\begin{array}{l}\text { The UK shall be disconnected at the end of the } \\
\text { transition period from all EU databases and net- } \\
\text { works. }\end{array}$ & $\begin{array}{l}\text { A company's activities related to such databases will likely be moved to } \\
\text { an EU MS and separate workflows would be established for UK. }\end{array}$ \\
\hline $\begin{array}{l}\text { The UK shall no longer be a part of the EU insti- } \\
\text { tutions and governance structures. Different regu- } \\
\text { latory pathways for approval of medicines are } \\
\text { expected. }\end{array}$ & $\begin{array}{l}\text { Marketing authorizations (MAs) for medicinal products will need to be } \\
\text { transferred to an affiliate established in the EU. Future MAs may need } \\
\text { to follow a different regulatory pathway than the EU. } \\
\text { However, under the current negotiatons', medicinal products or medical } \\
\text { devices already placed on the market by the end of the transition } \\
\text { period can continue to be made available on the UK market and the EU } \\
\text { Single Market. }\end{array}$ \\
\hline $\begin{array}{l}\text { Batch testing and product release of medicines in } \\
\text { the EU from a third country }\end{array}$ & $\begin{array}{l}\text { In case no Mutual Recognition Agreement (MRA) exists, it is necessary } \\
\text { to re-test medicines, for batch release, in which concerns eg product } \\
\text { specification (quantitative and qualitative), packaging quality control, } \\
\text { shipping/storage measures. } \\
\text { These processes are of course streamlined if an MRA is in place. }\end{array}$ \\
\hline $\begin{array}{l}\text { World Trade Organization ('WTO') rules to be } \\
\text { applied, in case separate agreements are conclud- } \\
\text { ed with WTO members }\end{array}$ & $\begin{array}{l}\text { Depending on the terms of each agreement concluded by UK with each } \\
\text { WTO member. }\end{array}$ \\
\hline
\end{tabular}

sional, or to the contract research organization (from its processor position) and eventually to the sponsor of the clinical trial which is the personal data controller, irrespective of whether it has or not access to the health data directly. Clearly identifying each role is very important for the future use of data. This information is most likely submitted in an aggregate manner to public authorities or in public databases, either in the context of having a medicinal product approved or in order to comply with reporting obligations. In this process, the controller has to look after it, ie identify and implement the appropriate measures.

In terms of records keeping, the GDPR requirements are very likely to be valid in any Brexit scenario: 'hard', 'soft' or BINO. When conducting clini- cal trials, either by EU-based companies (the sponsor, the CRO, other participants in the clinical trial who take up a processor's role) or with EU-based trial subjects, the GDPR requirements will need to be complied with and duly documented.

According to the GDPR and to the British Data Protection Act implementing the GDPR, the ICFs must contain clear information about what happens with the data. The information to be provided is detailed in articles 13 and 14 of the GDPR and in article 61 of the UK's Data Protection Act. The requirements for compliance are increased compared to directive 95/46/EC. This imposes in most cases a revision of the ICFs. In certain cases, where the additional information to be provided is not substantial, it can be transmitted as a notification to the trial sub- 
jects in a standard wording made available by the UK National Health Service (NHS). ${ }^{14}$ The wording is provided in several versions, tailored to the status of the clinical trial (ie study unapproved, study approved but still recruiting participants, study approved and participants were recruited before the entering into force of the GDPR on 25 May 2018 or the participants completed (an already approved) study by 25 May 2018). When using the standard NHS wording, there is no need to notify the health authority, because it does not approve the ICF in the first place. As to the Ethics Committee, the point of whether it needs to be informed or not may be directly discussed with them, as the approach may differ from one Ethics Committee to another and even more so from country to country. By principle, providing more information to the trial subjects with respect to the use of their health data would not be considered a substantial change to the ICF, thus it may not be necessary to notify the Ethics Committee either.

In the above case, the process is rather streamlined and made independent of the outcome of Brexit. A legal impact assessment of Brexit also entails determining whether uncertainties persist in a certain area or whether there are directions that one can rely on.

\section{Legal Basis for Processing Health Data in Clinical Trials}

The matter of gathering consent is a much-discussed topic. It will not be treated at length here. However, certain practical measures are of particular importance, as many questions arose with regard to the le-

14 NHS: Health Research Authority, 'Transparency' <https://www .hra.nhs.uk/planning-and-improving-research/policies-standards -legislation/data-protection-and-information-governance/gdpr -guidance/what-you-need-do/transparency/> accessed 13 November 2018.

15 European Data Protection Board, Opinion 3/2019 concerning the Questions and Answers on the Interplay between the CTR and the GDPR (art 70.1.b) adopted on 23 January 2019, s 2.1, para 11.

16 Information Commissioner's Office, 'Lawful Basis for Processing Consent' $34<$ https://ico.org.uk/media/for-organisations/guide-to -the-general-data-protection-regulation-gdpr/consent-1-0.pdf>accessed 13 November 2018.

17 Recital 45 GDPR. See also European Data Protection Board, Opinion 3/2019 concerning the Questions and Answers on the Interplay between the CTR and the GDPR (art 70.1.b) adopted on 23 January 2019. gal basis for processing the health data in a clinical trial in light of the GDPR. On a preliminary note, the following considerations are valid for both the postBrexit UK (due to implementation of GDPR during the UK's time as an EU MS) and to the remaining as well as future EU MS.

Upon agreeing to participate in a clinical trial (via the ICF as legal instrument), trial subjects are informed about the entire trial process and what exactly it entails. For instance, the ICF would entail details on the purposes of the trial and thus the purposes of processing of their health data, like: genotyping, collecting pharmacogenomics sample, biomarkers etc. Some of these objectives of the trial may be an optional part of the study to which the trial subject would then agree on a case by case basis. All the personal data processing operations involved in the conduct of a clinical trial related to the reliability and safety of medicines (eg safety reporting, archiving of the clinical trial master file and the medical files of subjects) fall under art. 6(1)(c) - compliance with a legal obligation. ${ }^{15}$ The processing operations related purely to scientific research can be conducted pursuant to several legal bases under article 6 GDPR:

- article 6(1)(a) consent (possible, but generally not a suitable basis) or pursuant to article 6(4) secondary use, where the patient agreed to take part in the study. Special attention should be paid to not confusing the ethnical or legal obligation to gather the patients' consent to participate in the study, with the consent pertaining to personal data processing. ${ }^{16}$ Where a patient provided its consent to processing health data for the purpose of receiving treatment, article $=6(4)$ GDPR allows that health data to be further processed for scientific research purposes (thus the processing takes place thanks to the permitted secondary use).

- article 6(1)(e) public interest, when EU or EU Member State law grants a public authority or even private body a mandate to conduct clinical trials (among other tasks). ${ }^{17}$

- in some cases, article 6(1)(f) legitimate interests of the controller, thus absent the data subject's consent, provided that safeguards are in place.

Processing special categories of data must be based on both an article 6 legal basis and an article 9 condition. Where the trial subject agrees to take part in the study (in its entirety or only to parts thereof), its 
consent for the processing of health data is implied. One cannot agree to participate in a clinical trial and not agree to the processing of the data, because such processing is inherent to carrying out the main activity (the research). What is even more pertinent in assessing explicit consent as a potential legal basis, is the patient's capacity to withdraw from the research and have their data deleted. If patients can withdraw from the study and ask for their health data to be deleted or anonymized, the outcome of the research is impaired, because it either becomes unrepresentative or the effects / safety cannot be monitored anymore. Hence, even though patients are able to withdraw from a study, they cannot ask for the health data gathered up to the time of the withdrawal to not be used anymore. There is, thus, no collection of explicit consent for personal data processing purposes under art. 9 GDPR. In an attempt to clarify, the GDPR provides that 'consent should not be regarded as freely given if the data subject has no genuine or free choice or is unable to refuse or withdraw consent without detriment'. ${ }^{18}$ The legal basis for processing such health data is the scientific research purposes, under article 9(2)(j) GDPR and, in the UK's case, as supplemented by Part I of Schedule 1 to the Data Protection Act 2018. Later on, where the health data (or the results of the analysis of this data) is stored over a longer period of time, for monitoring purposes, ${ }^{19}$ the legal basis for processing is ensuring high standards of quality and safety of health care, medicinal products, or medical devices, under article 9(2)(i) GDPR. Identifying the correct legal basis for processing is very important as data protection authorities in the EU already demonstrated they are taking the GDPR rules seriously and are not willing to close the eyes to any blind spots exposed by private parties from third countries.

On a slightly different note, where controllers prefer to turn to explicit consent as their legal basis for processing, it is worth looking into how the CTR impacts the GDPR and determines a particular read of the latter. While the rule is that consent should be given per purpose of processing, Recital 33 GDPR acknowledges that 'data subjects should be allowed to give their consent to certain areas of scientific research when in keeping with recognized ethical standards for scientific research.' The Recital further provides that it should be ensured that consent can be given only to certain research areas or to parts of research projects.

\section{Further Conditions in the UK's Data Protection Act 2018 to Processing Special Categories of Personal Data}

The UK Data Protection Act 2018 amends article 9 GDPR in certain points: ${ }^{20}$

- the data subject can always provide its explicit consent to the processing of special categories of personal data concerning it; the GDPR gave the possibility to EU member states to prohibit the data subject to provide such consent

- processing for public health purposes can only be conducted if it (1) is in the public interest and (2) is carried out by either a healthcare professional or another person owing a duty of confidentiality ${ }^{21}$

- scientific research ${ }^{22}$ can be conducted if it (1) is in the public interest and (2) the following cumulative safeguards are provided: ${ }^{23}$

- the processing is not likely to cause substantial damage or substantial distress to a data subject

- measures or decisions with respect to a particular data subject can only be envisaged if the purposes of processing include approved medical research, ie medical research carried out by a person who obtained approval from a research ethics committee or from a body appointed by relevant UK authorities (eg government department, relevant NHS body, research institutions etc.)

As the ultimate responsible entity for the clinical trial, UK sponsors or sponsors who endorse a clinical trial with a site in the UK must also be mindful of the rules for transfers of data between EU and third countries.

\section{Transfers of Data between EU and Third Countries}

The UK's third country status means, inter alia, that even with the GDPR already implemented in the UK

\footnotetext{
18 Recital 43 GDPR.

19 Eg pharmacovigilance activities carried out by the marketing authorization holder (MAH).

20 Data Protection Act 2018 c 12, Schedule 6, Part 1, para 12(a).

21 Data Protection Act 2018 c 12, Schedule 1, Part 1, para 3.

22 Data Protection Act 2018 c 12, Schedule 1, Part 1, para 4.

23 Data Protection Act 2018 c 12, s 19.
} 
body of laws, after the withdrawal date, the transfers of personal data between EU and UK will be carried out according to the special rules laid down in articles 44-50 (Chapter V) of the GDPR. ${ }^{24}$ Chapter V GDPR provides for several means of transferring data. Some of them are put in place by the private sector, depending on each company's needs. Other measures' availability is dependent on a decision taken at the public sector level, ie by the government and its specialised agencies. The choice between these means of transferring personal data depends on the rapidity with which an agreement will be reached on the matter by the EU and the UK. Until such time, it is up to each company (or group of companies) to sort out the legal framework of the data transfers it needs to make and also to document its choice. Accordingly, under Chapter V GDPR, personal data can be transferred between EU and third countries, based on: an adequacy decision, appropriate safeguards (of four types), specific derogations, or in the scenario of a non-repetitive transfer occurring in a special case. These are all means of transferring personal data that become relevant for the UK once it becomes a third country to the EU.

A data protection arrangement with 'more depth than an adequacy decision ${ }^{25}$ is currently being sought by the British government. The intention is to ensure smooth transfers of data between EU and UK, at both public and private sector, without the need to have each transfer pre-authorized by the authorities. An adequacy decision is applied for by a third country. Thus, a potential procedure to this end can only start as of withdrawal date. Upon successful examination, it is issued by the Commission, after necessarily taking into account the non-exhaustive list of factors in article 45 GDPR, to which other considerations can be added. Among these factors, of particular importance may be the UK's acceptance of the jurisdiction of the European Court of Justice. The EU bodies (Council, Parliament and Commission) have stated that an adequacy decision is preferred as 'the most secure option. ${ }^{26}$

The annexed table provides a comparative overview of the possibilities that private stakehold-

\footnotetext{
24 GDPR Chapter V - 'Transfers of personal data to third countries or international organisations'.

25 C C Cîrlig, L Puccio, op cit, 100.

26 C C Cîrlig, L Puccio, op cit, 100.
}

ers have until a decision is reached on an adequacy decision or the debated 'bespoken agreement on data protection'.

It is interesting to highlight the special case for non-repetitive transfers. Under certain conditions, such transfers can take place based on article $49(1) 2^{\text {nd }}$ paragraph GDPR, which favours scientific research, pursuant to Recital 113 GDPR: 'For scientific or historical research purposes or statistical purposes, the legitimate expectations of society for an increase of knowledge should be taken into consideration.'

\section{Data Protection Officers}

Brexit is likely to increase the UK-relevant tasks carried out by the Data Protection Officer ('DPO'). For one, after the UK's withdrawal from the EU, the DPO will have to establish communication with both the lead supervisory authority from one of the relevant EU Member States and with the Information Commissioner's Office ('ICO') in the UK, as the ICO will no longer participate in the EU cooperation mechanism. The DPO will also have increased tasks pertaining to data transfers between UK and EU. Absent an adequacy decision (which is likely to not be issued too soon, if any), for each transfer the DPO will need to make sure that appropriate safeguards are in place. When EU law ceases to apply to the UK, compliance documents accomplished for EU will need to be adapted to the UK jurisdiction.

A DPO of a company based in the UK who is offering goods or services to individuals in the EEA or monitoring the behaviour of individuals located in the EEA, will also need to be accompanied by a representative of that company in the EU (EEA, more precisely), if the UK company does not have a branch, office or other establishment in the EU. The appointed DPO is the most likely person to ensure timely communication with the representative, oversee its activity and adapt company documents with the representative's details.

\section{Conclusion}

The UK may try to borrow the Swiss example of concluding MRAs with the EU. During negotiations the 


\begin{tabular}{|c|c|c|c|c|c|}
\hline \multirow{2}{*}{\multicolumn{2}{|c|}{$\begin{array}{l}\text { Legal options for data } \\
\text { transfers }\end{array}$}} & \multirow[b]{2}{*}{$\begin{array}{c}\text { EU } \\
\text { Commis. } \\
\text { decision }\end{array}$} & \multicolumn{2}{|c|}{ Company decision } & \multirow[b]{2}{*}{ Details } \\
\hline & & & $\begin{array}{l}\text { With } \\
\text { DPA } \\
\text { approval }\end{array}$ & $\begin{array}{l}\text { Without } \\
\text { DPA } \\
\text { approval }\end{array}$ & \\
\hline Adequa & decision & $\checkmark$ & & & $\begin{array}{l}\text { - adopted by the Commission, via implementing or delegated acts } \\
\text { is equivalent to the corresponding EU regime } \\
\text { - enables free transfers, between EEA and the country granted adequacy decision }\end{array}$ \\
\hline \multirow{4}{*}{$\begin{array}{l}\text { Subject to } \\
\text { appropriate } \\
\text { safeguards, } \\
\quad \text { like: }\end{array}$} & $\begin{array}{l}\text { Standard } \\
\text { contractual } \\
\text { clauses } \\
\text { (SCCs) }\end{array}$ & & & $\checkmark$ & $\begin{array}{l}\text { - contractual wording issued by the Commission } \\
\text { - the clauses must be inserted into contracts tale quale, with no amendments } \\
\text { (additions or deletions) whatsoever } \\
\text { - otherwise, if the SCCS are modified in substance or if provisions are added, a prior } \\
\text { DPA authorisation of the contract will be necessary } \\
\text { - SCCs create a common standard of data protection between business partners } \\
\text { coming from jurisdictions with different levels of protection } \\
\text { - are to be used for transfers from EU controllers to controllers or processors outside } \\
\text { the EU/EEA }\end{array}$ \\
\hline & $\begin{array}{l}\text { Binding } \\
\text { corporate } \\
\text { rules (BCR) }\end{array}$ & & $\checkmark$ & & $\begin{array}{l}\text { - rules devised by a company for use with its affiliates } \\
\text { - submitted for approval by the competent DPA } \\
\text { - BCRs ensure lawful transfers, outside EEA, within a group of companies }\end{array}$ \\
\hline & $\begin{array}{l}\text { Codes of } \\
\text { conduct }\end{array}$ & & $\checkmark$ & & $\begin{array}{l}\text { - may be prepared by associations, to reflect the particular needs of the various } \\
\text { processing sectors } \\
\text { - subject to approval by the MS, DPAs, EDPB or the Commission } \\
\text { - can be adhered to by controllers or processors } \\
\text { - must be accompanied by binding and enforceable commitments, via contractual or } \\
\text { - mechanism newding instruments }\end{array}$ \\
\hline & $\begin{array}{l}\text { Certification } \\
\text { mechanisms }\end{array}$ & & $\checkmark$ & & $\begin{array}{l}\text { - certification mechanisms and seals and marks } \\
\text { - issued by certification bodies, DPAs or EDPB } \\
\text { - may be applied for by controllers or processors not subject to the GDPR for the } \\
\text { - must be accomponstrating compliance with the GDPR } \\
\text { - other legally binding instruments } \\
\text { - mechanism newly inserted by the GDPR }\end{array}$ \\
\hline \multicolumn{2}{|c|}{ Under specific derogations } & & & $\checkmark$ & $\begin{array}{l}\text { - eg explicit consent, performance of contract or pre-contractual measures, public } \\
\text { interest, vital interests }\end{array}$ \\
\hline \multicolumn{2}{|c|}{$\begin{array}{l}\text { Special case, for non- } \\
\text { repetitive transfers }\end{array}$} & & & $\checkmark$ & $\begin{array}{l}\text { Several conditions must be cumulatively complied with: } \\
\text { - none of the cases above could be chosen } \\
\text { - non-repetitive transfer } \\
\text { - legitimate interests of the controller are pursued } \\
\text { - suitable safeguards are in place }\end{array}$ \\
\hline
\end{tabular}

Annex I - Comparative Table of Means to Transfer Data between EU and Third Countries

UK pointed to the example ofNorway and Switzerland having in place agreements submitted to independent arbitration instead of the sole ECJ jurisdiction. But one should be mindful of how long of a process that was for Switzerland, and that the EU and Switzerland were in a process of approaching, not separating from each other. From a legal standpoint, the EU-Swiss or EU-Norwegian MRAs do include provisions on how the case law of one jurisdiction ought to be taken into account by the other. The EU-UK negotiations also currently take into consideration providing for a dispute resolution process involving both an arbitration panel and the ECJ for matters related to the interpretation of EU law.

The UK publicly declared in various instances that they are positive about leaving the EU, but also very keen in maintaining certain EU rules or other privileges brought about by EU membership. On the EU side, it was made clear that a non-member cannot have the same EU privileges while not assuming corresponding obligations. Given this discrepancy many have shift their attention towards measures open to the private sector in order to mitigate the risk entailed by the current uncertainties.

For life sciences, these measures may concern marketing authorisations, orphan drug designations, SME status and other regulatory measures. 